\title{
AnI open Public perceptions of coronary events risk factors: a discrete choice experiment
}

\author{
Yazid N Al Hamarneh, ${ }^{1}$ Ashley Agus, ${ }^{2}$ Danny Campbell, ${ }^{3}$ Grainne E Crealey, ${ }^{2}$ \\ James C McElnay ${ }^{4}$
}

To cite: Al Hamarneh YN, Agus A, Campbell D, et al. Public perceptions of coronary events risk factors: a discrete choice experiment. BMJ Open 2012;2:e001560. doi:10.1136/bmjopen-2012001560

- Prepublication history and additional material for this paper are available online. To view these files please visit the journal online (http://dx. doi.org/10.1136/bmjopen2012-001560).

This article has not been subsequently submitted to any other journal.

Received 30 May 2012 Accepted 6 August 2012

This final article is available for use under the terms of the Creative Commons Attribution Non-Commercial 2.0 Licence; see

http://bmjopen.bmj.com

${ }^{1}$ EPICORE Centre/COMPRIS, Department of Medicine, University of Alberta, Edmonton, Canada ${ }^{2}$ Northern Ireland's Clinical Research Support Centre, Education and Research Centre, Royal Hospitals, Belfast, UK

${ }^{3}$ School of Biological Sciences, Gibson Institute for Land, Food and Environment, Queen's University Belfast, Belfast, UK

${ }^{4}$ School of Pharmacy, Queen's University Belfast, Belfast, UK

Correspondence to Prof James C McEInay; j.mcelnay@qub.ac.uk

\section{ABSTRACT}

Objectives: To assess public perceptions of coronary heart disease $(\mathrm{CHD})$ risk factors.

Design: Discrete choice experiment questionnaire. Setting: Six provincial centres in Northern Ireland. Participants: 1000 adults of the general public in Northern Ireland.

Primary and secondary outcomes: The general public's perception of $\mathrm{CHD}$ risk factors. The effect of having risk factor(s) on that perception.

Results: Two multinomial logit models were created. One was a basic model (no heterogeneity permitted), while the other permitted heterogeneity based on respondents' characteristics. In both models individuals with very high cholesterol were perceived to be at the highest risk of having a coronary event. Respondents who reported having high cholesterol perceived the risk contribution of very high cholesterol to be greater than those who reported having normal cholesterol. Similar findings were observed with blood pressure and smoking. Respondents who were male and older perceived the contribution of age and gender to be lower than respondents who were female and younger.

Conclusions: Respondents with different risk factors perceived such factors differently. These divergent perceptions of CHD risk factors could be a barrier to behavioural change. This brings into focus the need for more tailored health promotion campaigns to tackle CHD.

\section{INTRODUCTION}

Coronary heart disease (CHD) is attributable to a number of risk factors, which can be classified as modifiable and non-modifiable. ${ }^{1}$ There are various approaches that can be used to calculate an individual's risk of having a coronary event using these risk factors, one of the most commonly used approaches being the Framingham equation ${ }^{2}$ which arose from the results of the Framingham Heart Study. This study began in 1948 and set out to identify the common factors that contribute to CHD by following a large cohort of asymptomatic patients over a prolonged period. By analysing the characteristics of the patients who

\section{STUDY SUMMARY}

Article focus

- How would individuals perceive various coronary heart disease (CHD) risk factors.

- Would having risk factor(s) affect the individual's perception of the CHD risk factors.

Key messages

- Respondents were mistaken in their perception of the contribution of individual CHD risk factors.

- Respondents with different risk factors perceived such factors differently.

- These mistaken and divergent perceptions of CHD risk factors could be a barrier to behavioural change. This brings into focus the need for more tailored health promotion campaigns to tackle CHD.

Strengths and limitations of this study

- To our knowledge this is the first study which uses discrete choice experiment methodology to assess the general public's perceptions of CHD risk factors. This methodology allows the assessment of the individual's perception of $\mathrm{CHD}$ risk factors and also provides an opportunity to take a closer look at the risk contribution which the individual places on different risk factors.

- Despite using a convenience sample the characteristics of the sample corresponded closely with the general population in Northern Ireland with the exception of an over-representation of smokers.

- The choice sets used had not been formally validated, however, it was assumed before conducting the study that individuals, with different risk factors, would perceive such factors differently and this was confirmed upon the analysis of the data. This confirms the method's internal validity (which assesses the extent to which the results are consistent with prior expectations) and is in line with the evidence that individuals will answer a discrete choice experiment in a consistent and internally valid manner.

suffered from CHD in the follow-up period, gender-specific equations were formulated to predict the risk of having a coronary event in the next 10 years in patients according to their age, diabetic status, smoking status, blood pressure, total cholesterol or low-density 
lipoprotein (LDL) cholesterol and high-density lipoprotein (HDL) cholesterol values. ${ }^{2}$

Considering the well-established link between health and individuals' knowledge about the disease, ${ }^{3}$ it is not surprising that many health promotion strategies attempt to motivate preventative health behaviours by addressing the public's knowledge of diseases and their risk factors. Nevertheless, individuals continue to engage in unhealthy behaviours even when the risks are well known. For example, according to the Office for National Statistics, approximately one-quarter of individuals aged 16 and over in Great Britain continue to smoke despite the explicit health warning labels on cigarette packets. ${ }^{4}$

Knowing that individuals continue to engage in unhealthy behaviour despite knowing the risks and given that prevention, as opposed to cure, is the most effective way to deal with $\mathrm{CHD},{ }^{15}$ it is of major interest to know how the general public perceive CHD risk factors and whether their perceptions are in line with their actual CHD risk. Knowledge of this information will help to address the misconceptions held by the general public and ultimately lead to more successful approaches to tackle CHD.

Individuals' perceptions and knowledge of different CHD risk factors have been studied using traditional questionnaires; ${ }^{6-9}$ however, none of the studies to date have used discrete choice experiment (DCE) methodology to assess the general public's perceptions of these risk factors. The use of DCE methodology in healthcare research is increasing as it allows researchers to investigate individuals' preferences regarding certain services or treatment approaches. ${ }^{10}$ This methodology also provides an opportunity to take a closer look at the relative importance which the individual places on different characteristics. $^{11} 12$

The main aim of the present study was to assess the perceptions of members of the general public (in Northern Ireland) of various factors which increase the risk of having a coronary event and to assess if these perceptions are affected by their personal risk profile.

\section{METHODS}

Study design

A total of 1000 adults (without CHD) from Northern Ireland were interviewed using DCE methodology.

\section{DCE design}

Van Helvoort-Postulart et $a l^{12}$ have outlined that the construction of a DCE consists of the following three steps.

\section{Determining the 'attributes' of interest}

The risk factors age, gender, total cholesterol, HDL, blood pressure, diabetic status and smoking status, which are used in Framingham equation to estimate an individual's risk of having a coronary event in the next 10 years, were used as the DCE attributes.

\section{Setting levels for these 'attributes'}

The levels of these risk factors, as determined in the Framingham equation, were used as the 'attribute-levels'.

In the Framingham equation, points are allocated to each level of the risk factors according to gender and then summed to give a score which is used to assign the risk of having a coronary event in the next 10 years. The risk of having a coronary event in the next 10 years is expressed as a percentage and is categorised into three categories:

- $<10 \%$ low risk

- 10-20\% moderate risk

- $>20 \%$ high risk. ${ }^{13}$

On the basis of the Framingham equation, gender attribute had two levels ('male' and 'female'); the age attribute had nine levels (ranging between 30 and 74 years in 5-year intervals); the total cholesterol, the HDL and the blood pressure attributes had five levels ('very low', 'low', 'moderate', 'high' and 'very high'); while the diabetic status and the smoking status attributes had two levels (ie, 'present' and 'absent').

As there were three attributes with five 'attribute-levels' (blood pressure, total cholesterol and HDL), one attribute with nine 'attribute-levels' (age) and three attributes with two 'attribute-levels' (gender, smoking status and diabetic status), $9000\left((5)^{3} \times(9) \times(2)^{3}\right)$ combinations for both genders were possible (4500 combinations for each gender).

\section{Constructing the choice sets which are composed of the 'attributes' at different 'attribute-levels'}

Choice sets were constructed by randomly combining risk factors at different levels to give different risks of having a coronary event in the next 10 years. The randomly constructed choice sets were used in a pilot survey, where 100 members of the general public were presented in a face-to-face interview with different number of choice sets (ranging between 8 and 16 choice sets) to explore how they would deal with the discrete choice experiment and to check how many choice sets they could process while still remaining fully engaging with the researcher.

Although it has been reported in the literature that individuals can process up to 16 choice sets comfortably, ${ }^{14}$ the pilot work established that 8 choice sets was a more appropriate number to be included in each questionnaire to avoid prolongation of the interview beyond the point where full engagement of the respondents was achievable.

Respondents in the pilot study were found to be more familiar with the negative effects of cholesterol and found the protective effects of HDL difficult to comprehend. For this reason, the HDL was held constant within the final version of the choice sets, that is, it was held at the level of $1.30-1.55 \mathrm{mmol} / 1$ since this level does not contribute to the overall risk score. With the HDL held constant, the number of possible combinations was 
reduced considerably from 4500 to 900 for each gender $\left(1800\right.$ in total $\left.\left((5)^{2} \times(9) \times(2)^{3}\right)\right)$.

Since the risk factors used in the Framingham equation have different effects at different levels, and since the main aim of the present study was to assess the general public's perceptions of such risk factors, it was agreed by the authors that the risk of having a coronary event in the next 10 years should be held constant in all the choice sets.

The choice sets were designed such that the exploration of the respondent's perception of risk was limited to a risk of $20 \%$, since this is the cut-off point between the moderate-risk and the high-risk categories. Furthermore, the number of risk factor combinations produced at the $20 \%$ risk level (124 combinations) was the closest number of combinations divisible by eight (the number of choice sets to be used in the present study following piloting). To make the number of combinations divisible by 8,4 of the 124 selected combinations were chosen randomly to be repeated to make 128 combinations.

Using the approach described by Ryan et $a l^{15}$, choice sets were then constructed by randomly pairing the 128 combinations to create 64 choice sets. These were then divided to give eight blocks of eight choice sets, with each block contained within a different version of the questionnaire, each to be completed by one-eighth of the respondents. ${ }^{15}$

To measure their perception of CHD risk factors, respondents were presented with eight choice sets; each composed of two hypothetical individuals and they were asked to choose the individual they perceived to be at greater risk of having a coronary event in the next 10 years. A 'don't know' option was available when respondents could not make a choice between the options presented (table 1).

\section{Participants and data collection}

Ethical approval to carry out this study was granted by the Queen's University Belfast, School of Pharmacy Ethics Committee.

Data were collected as part of a survey which investigated CHD health knowledge and behaviour among members of the general public in Northern Ireland. ${ }^{9}$ Data obtained in the pilot study referred to above were not included in the final analysis.

\begin{tabular}{|c|c|c|}
\hline Person A & Person B & \\
\hline 60-year-old female & $\begin{array}{l}\text { 55-year-old } \\
\text { male }\end{array}$ & \\
\hline Very high cholesterol & Low cholesterol & \\
\hline High blood pressure & $\begin{array}{l}\text { Very high blood } \\
\text { pressure }\end{array}$ & Don't know \\
\hline Non-diabetic & Diabetic & $A$ \\
\hline Smoker & Non-smoker & $\mathrm{B}$ \\
\hline
\end{tabular}

Once the survey instrument had been refined, the questionnaire was administered face-to-face to a convenience sample of 1000 members of the general public in Northern Ireland (dispersed over six provincial centres; the methodology of administering the questionnaire is described elsewhere). ${ }^{9}$ A researcher from Queen's University Belfast approached the members of the public, then explained the nature of the survey and indicated that the questionnaire would take approximately $10 \mathrm{~min}$ to complete. Having been given this information, members of the public were asked if they were willing to participate in the study. The researcher spent approximately 2 weeks in each provincial centre, where members of the public were approached in a variety of outdoor locations (eg, parks, city centre shopping areas and bus stops) on different days and times (including evenings, weekends and bank holidays) ${ }^{9}$

\section{Data analysis}

All the collected data were entered into Nlogit 3 software. The data were analysed using multinomial logit (MNL) models (which represent the association between the probability of a particular choice being made by an individual and one or more independent variables which reflect attributes of the choice or the individual). In the MNL models $\hat{\beta}$ represents the MNL model coefficient which indicates the contribution of the independent variable to the final model (variables with a larger $\hat{\beta}$ have a higher contribution in the final model). McFadden's rho ${ }^{2-}$ measures the goodness-of-fit for the model (McFadden's $\mathrm{r}^{2}$ values between 0.2 and 0.4 are considered $\operatorname{good} \mathrm{fit}^{16}$ ). The t-ratio is usually used in the MNL model to assess the significance of the contribution of each independent variable to the MNL model (|t-ratio $\mid>1.96$ is considered significant). ${ }^{16}$

\section{RESULTS}

\section{Demographics and clinical characteristics}

Of the 1000 respondents interviewed, 14 were excluded from the analyses as they did not disclose their age and/or did not know their cholesterol or blood pressure status. Thus, the final usable sample consisted of 986 respondents. In the analyses the cholesterol and the blood pressure variables were dichotomised into normal and high. Age was dichotomised into younger respondents ( $<50$-years-old) and older respondents $(\geq 50 \text {-years-old })^{17} 18$ to facilitate evaluation of the impact of these risk factors on the study outcomes.

The demographic and self-reported clinical characteristics of the study respondents are presented in table 2. Of the 986 respondents, more than half were males $(54.8 \%)$; almost two-thirds were less than 50-years-old $(65 \%)$; just less than one-fifth reported having high cholesterol (18\%) and high blood pressure (17.2\%); less than one-tenth had diabetes $(7.7 \%)$; less than half reported being current smokers $(41.6 \%)$ while almost one-quarter reported smoking in the past $(23.8 \%)$. 
Table 2 The demographic and self-reported clinical characteristics of the study respondents $(n=986)$

\begin{tabular}{lll}
\hline Characteristics & Frequency & Percent \\
\hline Gender & & \\
Male & 540 & 54.8 \\
Female & 446 & 45.2 \\
Age (years) & & \\
$20-49$ & 641 & 65 \\
$50-79$ & 345 & 35 \\
Cholesterol level & & \\
$\quad$ Normal & 809 & 82 \\
$\quad$ High & 177 & 18 \\
Blood pressure level & & \\
$\quad$ Normal & 816 & 82.8 \\
$\quad$ High & 170 & 17.2 \\
Diabetic status & & \\
$\quad$ Diabetic & 76 & 7.7 \\
$\quad$ Non-diabetic & 910 & 92.3 \\
Smoking status & & \\
$\quad$ Current smoker & 410 & 41.6 \\
$\quad$ Ex-smoker & 235 & 23.8 \\
$\quad$ Non-smoker & 341 & 34.6 \\
\hline
\end{tabular}

\section{Discrete choice experiment analysis}

Two MNL models were constructed: Model 1 (table 3) is the basic MNL model, where the respondents' reported characteristics were not taken into account in the analysis. Model 2 (table 4) permits heterogeneity based on respondents' reported characteristics (ie, respondents' characteristics were taken into account in the analysis).

In Model 1, when choosing which individual was at greater risk of having a coronary event in the next 10 years, respondents perceived individuals with very

Table 3 The basic multinomial logit model (Model 1)

\begin{tabular}{lll}
\hline Variable & $\hat{\beta}^{*}$ & t-Ratiot \\
\hline Gender & 0.285 & 6.4 \\
Age & 0.067 & 11.4 \\
Very low cholesterol & -0.902 & -7.0 \\
Low cholesterol & -0.741 & -16.2 \\
High cholesterol & 0.574 & 9.5 \\
Very high cholesterol & 1.613 & 19.3 \\
Very low blood pressure & -0.735 & -10.3 \\
Low blood pressure & -0.629 & -9.4 \\
High blood pressure & 0.641 & 13.4 \\
Very high blood pressure & 0.957 & 12.4 \\
Diabetic status & 0.661 & 14.1 \\
Smoking status & 1.358 & 31.3 \\
Don't know & 1.210 & 2.9 \\
Log-likelihood ratio & -4189.758 & \\
$r^{2} \ddagger$ & 0.517 & \\
\hline
\end{tabular}

${ }^{*} \hat{\beta}$ represents the multinomial logit (MNL) model coefficient which indicates the contribution of the independent variable to the final model.

tt-Ratio is usually used in the MNL model to assess the significance of the contribution of each independent variable to the MNL model ${ }^{16}$.

$\ddagger$ McFadden's $r^{2}$ measures the goodness-of-fit for the model ${ }^{16}$ high cholesterol to be at the highest risk. This was followed closely by smoking. The results also indicate that the respondents considered very high and high blood pressure, diabetes and high cholesterol to increase the risk of having a coronary event in the next 10 years. Moreover, respondents considered non-modifiable risk factors to also contribute to having a coronary event, in particular, respondents deemed males and older respondents to be at higher risk of having a coronary event in the next 10 years. Respondents regarded individuals with very low and low cholesterol and very low and low blood pressure to be at lower risk of having a coronary event in the next 10 years.

In Model 2, respondents perceived individuals with very high cholesterol to be at the highest risk of having a coronary event in the next 10 years. Respondents, who reported that they themselves had high cholesterol, perceived the contribution of very high cholesterol to the overall risk of having a coronary event in the next 10 years to be greater than those who reported having normal cholesterol. The same findings were observed with blood pressure and smoking, that is, respondents who reported having high blood pressure and smoking currently, perceived the contribution of very high blood pressure and smoking (respectively) to the overall risk of having a coronary event in the next 10 years to be greater than those who reported having normal blood pressure or reported being an ex-smoker or a non-smoker.

Male respondents perceived the contribution of the male gender to the overall risk of having a coronary event in the next 10 years to be lower than female respondents. Similarly, older respondents perceived the contribution of age to the overall risk of having a coronary event in the next 10 years to be lower than younger respondents.

The risk associated with diabetes was found to be similar for diabetic and non-diabetic respondents.

As indicated by the increase in the log-likelihood, Model 2 provides a better fit to the data, when compared with Model 1.

\section{DISCUSSION}

\section{Risk factors perception}

In the present study, respondents perceived the contribution of very high cholesterol to the overall risk of having a coronary event in the next 10 years to be the highest, followed by smoking and very high blood pressure. Respondents were mistaken, as the main individual contributors to the overall risk of having a coronary event in the next 10 years are being in an older age group ( 50 years and older), followed by very high cholesterol and very high blood pressure in males, while in females the main individual contributors are being in an older age group ( 50 years or older) followed by diabetes, very high cholesterol and very high blood pressure. .

In the present study respondents with different risk factors perceived such factors differently, a finding 
Table 4 Heterogeneous multinomial logit model (Model 2)

\begin{tabular}{|c|c|c|c|}
\hline Variable & Characteristic & $\hat{\beta}^{*}$ & t-Ratio† \\
\hline \multirow[t]{2}{*}{ Gender } & Male & 0.223 & 4.6 \\
\hline & Female & 0.344 & 6.9 \\
\hline \multirow[t]{2}{*}{ Age } & Aged $20-49$ years & 0.069 & 11.5 \\
\hline & Aged $50-79$ years & 0.054 & 10.4 \\
\hline \multirow[t]{2}{*}{ Very low cholesterol } & Normal cholesterol & -0.927 & -7 \\
\hline & High cholesterol & -0.941 & -5.2 \\
\hline \multirow[t]{2}{*}{ Low cholesterol } & Normal cholesterol & -0.714 & -14.2 \\
\hline & High cholesterol & -0.756 & -7.8 \\
\hline \multirow[t]{2}{*}{ High cholesterol } & Normal cholesterol & 0.584 & 9.2 \\
\hline & High cholesterol & 0.607 & 5.9 \\
\hline \multirow[t]{2}{*}{ Very high cholesterol } & Normal cholesterol & 1.610 & 19 \\
\hline & High cholesterol & 1.653 & 15.2 \\
\hline \multirow[t]{2}{*}{ Very low blood pressure } & Normal blood pressure & -0.729 & -9.7 \\
\hline & High blood pressure & -0.775 & -4.3 \\
\hline \multirow[t]{2}{*}{ Low blood pressure } & Normal blood pressure & -0.651 & -9.2 \\
\hline & High blood pressure & -0.747 & -5.7 \\
\hline \multirow[t]{2}{*}{ High blood pressure } & Normal blood pressure & 0.677 & 13.2 \\
\hline & High blood pressure & 0.639 & 6.2 \\
\hline \multirow[t]{2}{*}{ Very high blood pressure } & Normal blood pressure & 0.946 & 12 \\
\hline & High blood pressure & 0.973 & 8.5 \\
\hline \multirow[t]{2}{*}{ Diabetic status } & Non-Diabetic & 0.660 & 13.8 \\
\hline & Diabetic & 0.657 & 7.5 \\
\hline \multirow[t]{3}{*}{ Smoking status } & Current smoker & 1.564 & 28.7 \\
\hline & Ex-smoker & 1.293 & 22.2 \\
\hline & Non-smoker & 1.203 & 23.5 \\
\hline Don’t know & & 1.213 & 2.9 \\
\hline Log-likelihood & & -4158.543 & \\
\hline$r^{2} \ddagger$ & & 0.520 & \\
\hline
\end{tabular}

which was also reported by Weinstein et $a l^{19}$ who reported that smokers in the USA perceived the risk of smoking differently, when compared with non-smokers, when they were presented with questions which measure their belief about smoking risks.

In the present study, respondents who reported having hyperlipidaemia, hypertension or who were smokers, perceived the contribution of these individual risk factors to the overall risk of having a coronary event in the next 10 years to be greater than those who did not report having such risk factors. This finding can perhaps be explained by the fact that the respondents were presented with hypothetical scenarios and were not asked about their own risk. Individuals may have been convinced by the general health risk messages regarding these risk factors, yet still believe that other individuals rather than themselves should take the required corrective measures. ${ }^{20}$ Other researchers have found that smokers acknowledge the risk associated with smoking yet they still perceive themselves to be at lower risk compared with other smokers. ${ }^{19}$

In the present study the risk placed on diabetes was found to be similar for diabetic and non-diabetic respondents. This finding can be explained by the poor public knowledge about the link between diabetes and cardiovascular disease. The present finding is supported by the results of Jafary $e t a l^{7}$ who assessed CHD knowledge in a Pakistani population and reported that less than $2 \%$ of their respondents highlighted diabetes as a CHD risk factor.

In the present study, males perceived the contribution of the male gender to the overall risk of having a coronary event in the next 10 years to be lower, when compared with females. Also, older respondents perceived the contribution of age to be lower, when compared with younger respondents. This can be explained by the fact that individuals tend to process health risk information in a biased way. ${ }^{20-22}$ This 'defensive' bias is driven by the individuals' motivation to protect their sense of self-integrity and their view of themselves as 'adaptively and morally adequate ${ }^{, 23}$ and also by the fact that individuals tend to possess an unrealistic optimism of their own risk and susceptibility. ${ }^{19}$

\section{Importance of targeted health promotion campaigns}

The present study highlighted that respondents were mistaken in their perception of the contribution of individual CHD risk factors. It also highlighted that respondents with different risk factors perceived such factors differently. These mistaken and divergent perceptions of CHD risk factors could be a barrier to behavioural change. 
This brings into focus the need for more tailored health promotion campaigns to tackle CHD. Nollen $e t a t^{24}$ have proposed using group-targeted campaigns to allow individuals within particular risk groups to receive advice based on the common group characteristics. Also a tailored approach was requested by CHD patients who took part in a study conducted by Leathem et $a l^{25}$. In the latter study, CHD patients' opinions were taken into account when designing a health education booklet which could be used by their general practitioners. ${ }^{25}$

\section{Limitations}

The fact that a convenience sample was used may have introduced selection bias, however, on inspection, the characteristics of the sample corresponded closely with the general population in Northern Ireland ${ }^{26} 27$ with the exception of an over-representation of smokers. ${ }^{28}$

The choice sets used had not been formally validated; however, it was assumed before conducting the study that individuals, with different risk factors, would perceive such factors differently and this was confirmed upon the analysis of the data. This confirms the method's internal validity (which assesses the extent to which the results are consistent with prior expectations) and is in line with the evidence that individuals will answer a discrete choice experiment in a consistent and internally valid manner. ${ }^{10}$

\section{CONCLUSION}

Respondents with different risk factors had different perceptions of such factors. Also they were mistaken in their perceptions about the contribution of such factors to the overall risk of having a coronary event in the next 10 years. These divergent and mistaken perceptions of CHD risk factors could be a barrier to behavioural change. This brings into focus the need for more tailored health promotion campaigns to tackle CHD.

Acknowledgements The authors would like to acknowledge all the members of the public who participated in this study.

Contributors All the authors have helped in designing the study, conducting the analysis and writing the paper. YA also collected the data.

Competing interests None.

Ethics approval The Queen's University Belfast, School of Pharmacy Ethics Committee.

Provenance and peer review Not commissioned; externally peer reviewed.

Data sharing statement Please note that the paper that explains the data collection in details has been attached as a supplementary file.

\section{REFERENCES}

1. Pearson TA, Blair SN, Daniels SR, et al. AHA guide lines for primary prevention of cardiovascular disease and stroke: 2002 update: consensus panel guide to comprehensive risk reduction for adult patient without coronary or other atherosclerosis vascular disease. Circulation 2002;106:388-91.

2. Wilson PW, D'Agostino RB, Levy D, et al. Prediction of coronary heart disease using risk factor categories. Circulation 1998;97:1837-47.

3. Cowell $A$. The relationship between education and health behavior: some empirical evidence. Health Econ 2006;15:125-46.
4. Robinson S, Harris H. Smoking and drinking among adults. 2009 (online) http://www.ons.gov.uk/ons/search/index.html?newquery=smoking+and +drinking+among+adults (accessed 29 Nov 2011).

5. Scarborough $\mathrm{P}$, Bhatnagar $\mathrm{P}$, Wickramasinghe $\mathrm{K}$, et al. Coronary heart disease statistics. 2010 (online). http://www.bhf.org.uk/idoc. ashx?docid=9ef69170-3edf-4fbb-a202-a93955c1283d\&version=-1 (accessed 29 Nov 2011).

6. Potvin L, Richard L, Edwards AC. Knowledge of cardiovascular disease risk factors among the Canadian population: relationship with indicators of socioeconomic status. CMAJ 2000;162:S5-11.

7. Jafary $\mathrm{FH}$, Aslam $\mathrm{F}$, Mahmud $\mathrm{H}$, et al. Cardiovascular health knowledge and behaviour in patient attendants at four tertiary care hospitals in Pakistan-a cause for concern. BMC Public Health 2005;5:124-32.

8. Petricek G, Vrcic-Keglevic M, Vuletic G, et al. Illness perception and cardiovascular risk factors in patients with type 2 diabetes: cross-sectional questionnaire study. CMJ 2009;50:583-93.

9. Al Hamarneh YN, Crealey GE, McElnay JC. Coronary heart disease: health knowledge and behaviour. IJCP 2001;33:111-23.

10. Ryan M. Discrete choice experiments in healthcare. BMJ 2004;328:382

11. Ryan M, Bate A, Eastmond CJ, et al. Use of discrete choice experiments to elicit preferences. Qual Health Care 2001;10:i55--60.

12. Van Helvoort-Postulart D, Van Der Weijden T, Dellaert BG, et al. Investigating the complementary value of discrete choice experiments for the evaluation of barriers and facilitators in implementation research: a questionnaire survey. Implement Sci 2009;4:10-21.

13. Grundy SM, Cleeman JI, Merz CNB, et al. Implications of recent clinical trials for the national cholesterol education program adult treatment panel III guidelines. Circulation 2004;110:227-39.

14. Kruijshaar ME, Essink-Bot ML, Donkers B, et al. A labelled discrete choice experiment adds realism to the choices presented: preferences for surveillance tests for Barrett esophagus. BMC Medical Res Methodol 2009;9:31-40.

15. Ryan $M$, Netten $A$, Skatun $D$, et al. Using discrete choice experiments to estimate a preference-based measure of outcomean application to social care for older people. $J$ Health Econ 2006;25:927-44.

16. Hesnher DA, Johnson LW. Applied discrete-choice modelling London: Croom Helm Ltd 1981:48-51.

17. AL-Fiadh A, Andrianopoulos N, Duffy S, et al. Comparison of cardiovascular risk factor profile amongst younger ( $<50$ years) versus older age ( $\geq 50$ years) patients undergoing percutaneous coronary intervention: insights from a large multi-centre registry. Heart Lung Circ 2008;17:S99-100.

18. Prescott K, Le Jeune I. Self-poisoning in older people. Age Ageing. 2010;39:279.

19. Weinstein ND, Marcus SE, Moser RP. Smokers' unrealistic optimism about their risk. Tobacco Control 2005;14:55-9.

20. Harris PR, Napper L. Self-affirmation and the biased processing of threatening health-risk information. Pers Soc Psychol Bull 2005;31:1250-63.

21. Serman DK, Cohen GL. Accepting threatening information: self-affirmation and the reduction of defensive bias. Curr Dir Psychol Sci 2002;11:119-23.

22. Sherman DK, Nelson LD, Steele CM. Do messages about health risks threaten the self? Increasing the acceptance of threatening health messages via self-affirmation. Pers Soc Psychol Bull 2000;26:1046-58.

23. Steele CM. The psychology of self-affirmation: sustaining the integrity of the self. New York: Academic Press, 1988:261-3.

24. Nollen N, Ahluwalia JS, Mayo MS, et al. A randomized trial of targeted educational materials for smoking cessation in African Americans using transdermal nicotine. Health Educ Behavior 2007;34:911-27.

25. Leathem CS, Cupples ME, Byrne MC, et al. Using the opinions of coronary heart disease patients in designing a health education booklet for use in general practice consultations. Primary Health Care Res Development 2009;10:189-99.

26. Northern Ireland Statistics and Research Agency. Population comparison with other countries of the United Kingdom by age and sex. 2010 (online). http://www.nisra.gov.uk/demography/default. asp2.htm (accessed 29 Nov 2011).

27. O'Reilly D, Stevenson M. Selective migration from deprived areas in Northern Ireland and the spatial distribution of inequalities: implications for monitoring health and inequalities in health. Soc Sci Med 2003;57:1455-62.

28. Evandrou M, Falikingham J. Cigarette smoking and drinking behaviour in Northern Ireland 1986-2002: a cohort analysis. 2004 (online). http://www.dhsspsni.gov.uk/smoking_drinking_behaviour. pdf (accessed 29 Nov 2011). 